\title{
Democracy and the Internet: A Retrospective
}

\section{Charles Ess}

Department of Media and Communication, University of Oslo, Oslo, Norway

Email: c.m.ess@media.uio.no

Charles Ess is Professor of Media Studies, Department of Media and Communication, University of Oslo, Norway. He works at the intersections of philosophy, computing, applied ethics, comparative philosophy, and media studies, with specific focus on research ethics, Digital Religion, and virtue ethics in media and communication, including social robots. Recent publications include (editor), "Communication and Technology," The ICA Annals of Communication, 1 (3, 4: December, 2017). 


\section{Democracy and the Internet: A Retrospective}

In the late 1980s and early 1990s, the emerging internet and World Wide Web inspired both popular and scholarly optimism that these new communication technologies would inevitably "democratize" - in local organizations, larger civic and political institutions, and, indeed, the world itself. The especially Habermasand feminist-inspired notions of deliberative democracy in an electronic public sphere at work here are subsequently challenged, however, by both theoretical and empirical developments such as the Arab Winter and platform imperialism. Nonetheless, a range of other developments - from Edward Snowden to the emergence of virtue ethics and slow tech as increasingly central to the design of ICTs - argue that resistance in the name of democracy and emancipation is not futile.

Keywords: democracy, emancipation, Habermas, feminism, virtue ethics, slow tech, utopia, dystopia

\section{Introduction}

In the early 1990s, the internet had just emerged into more public use and awareness.

To be sure, there were extensive antecedents, circumscribed as computer-mediated communication (CMC) and initially explored popularly in the 1980 s by way of telephone-based networks such as America Online in the U.S. and the Minitel in France. But as the internet and then the World Wide Web (ca. 1992) rapidly diffused - first of all, within the United States and North America - in the early 1990s, these technologies evoked both utopian dreams and dystopian nightmares. On the bright side, both scholarly and popular discourse enthused that "wiring the world" with the internet would inevitably "democratize" - in local organizations, larger civic and political institutions, and, indeed, "the electronic global village" as attributed to Marshall McLuhan. More darkly, and perhaps most presciently: Neil Postman (1984), referring to George Orwell's 1984 and Aldous Huxley's Brave New World, argued that our electronic future risked devolving into a totalitarian state made possible by perfect surveillance - reinforced by our happy compliance with the unlimited pleasures and 
distractions offered by new technologies. To paraphrase, we fall in love with the technologies of our enslavement as we amuse ourselves to death.

In the following, I will trace out important highlights of both theoretical developments and empirical findings that in the subsequent 25 years take us well beyond the optimisms of the early democratization thesis. Especially the rise of Web 2.0 and, more recently, platform imperialism and the Daily Me argue that Postman was correct. But resistance is not futile - so far. Facebook can be partially tamed through legal action and protest. And virtue ethics - as emphasizing good lives of flourishing, not solely convenience and corporate profit - is being taken up in the design of ICTs, as part of broader developments towards Slow Tech and a post-digital society that open up new possibilities for more democratic and emancipatory futures. But to exploit these emancipatory potentials will require us to better understand, design, and utilize these technologies in the service of democracy and good lives, not simply consume them.

\section{From Habermas to the Daily Me}

Many the early arguments for the internet as democratizing rested on Habermas' conceptions of the ideal speech situation as central to free and open democratic deliberation (Ess 1996). Early modes of internet-facilitated communication - email, listservs, chatrooms- seemed well-suited to carefully crafting rational argument, attending to diverse voices, and coming to consensus based on the better argument rather than force and coercion (e.g., Habermas 1983).

Initially, these early conceptions were critiqued and transformed - first on theoretical levels, especially through feminist arguments that developed a more comprehensive synthesis of the rational, the affective and the narrative (Thorseth 2008). And vis-à-vis growing empirical documentation of how online discourse included abusive and violent speech directly contrary to the ideals of good argument and 
deliberative democracy (trolling, cyber-bullying, hate speech, etc.), theory began to adjust accordingly. So Barbara Becker and Josef Wehner argued in 2001 that online spaces could only offer us "partial publics," rather than some more broadly shared deliberative space (2001). Most presciently, Cass Sunstein (2001) highlighted the social and political dangers of fragmentation online, "the Daily Me" - what we now call filter bubbles that feed us views and information we already agree with. Especially as communication venues transformed with the emergence of Web 2.0, early optimism was further challenged on both theoretical fronts (e.g., various "post-“ critiques, beginning with postmodern through post-colonialism, etc.) and by practical developments, especially the increasing commercialization and consolidation of these communication spaces within the ownership and control of a few transnational corporations (Phelan and Dalhberg 2011).

\section{Things fall apart}

One index of the shift away from early optimism is Maria Bakardjieva's concept of "subactivism" (2009). This concept and its empirical instantiations - e.g., parents organizing via social media to call for improvements in their local kindergarten thereby emerge as sites of at least modest democratic protest and reform: these stand as middle grounds between grand utopias (Habermasian, feminist, and so on) and dystopias (Big Brother in various guises).

In 2010, the Arab Springs - followed by the Arab Winter - dealt an irrecoverable blow to early optimism. Initially it appeared that internet-facilitated communication - specifically, the social media venues of Facebook, Twitter, etc. helped democratization on the ground, beginning with Tunisia and then throughout the Arab world. But while social media clearly played an important role (Howard and Hussain 2013), the brutally harsh failures of these democratic movements (with the 
exception of Tunisia) forcefully demonstrated that such technologies are but one set of factors among many, e.g., social and political contexts, institutions, actors, culturally variable customs and norms, and so on. At best, these technologies can work as necessary but clearly not sufficient conditions for positive social and political change.

More fundamentally, the Arab Springs and Winter make explicit two primary flaws in the democratization thesis - namely, assumptions of technological determinism and technological instrumentalism. First, technological determinism accords an absolute power to new technologies. Again, "wiring the world" was claimed to inevitably result in greater freedom of expression, democratization, and so on (Ess 1996, 197-201). The Arab Winter is an irrefutable object lesson (among many others) that such simple determinism is simply false.

Second, technological instrumentalism claims that technologies are somehow value-neutral, "just tools." But as any number of empirical and theoretical analyses (e.g., within Science, Technology and Society (STS) as well as numerous feminist critiques) already made clear from the 1960s forward, all technologies embed both explicit and implicit values, and re-inscribe these through their use and applications. To ascribe democratizing power to the internet directly reflects its North American origins, and thereby directly contradicts the claims of technological instrumentalism. The Arab Winter - along with multiple other examples - shows precisely a central conflict between the values, norms, aims and so on embedded in internet technologies, on the one hand, and the often quite different norms, values, practices, and so on defining a "target" culture.

Certainly, philosophers, social scientists, and others pointed out these underlying assumptions and their flaws early on (Ess 1996, 2004). But what scholars and researchers may discern early on often requires such harsh, concrete examples as the 
Arab Winter in order for these insights to diffuse into a broader, more publicly shared understanding of technology.

In any case, these events and insights shaped further important theoretical developments, especially within critical theories and political economy. For example, Jodi Dean (2009) argues that instead of open spheres of free and democratizing discourse, the internet increasingly traps us in "communicative capitalism." In multiple ways - from filter bubbles to the basic commodification of "friendship" in social media - our communicative spaces work largely to reinforce existing beliefs and convictions, while undermining possibilities of challenging neoliberal capitalism as driving the construction, maintenance, and expansion of these systems (cf. Lindgren 2017).

This leads to more recent conceptions of "platform imperialism." As Dal Yong Jin $(2015,4)$ elaborates, "platform" refers to our entire range of communication, including Social Networking Sites, search engines, and smartphones. Jin goes on to show how these platforms are predominantly designed, implemented, and controlled by especially four transnational corporations (TNCs) -Apple, Google, Facebook, and Microsoft. At the same time, these platforms and corporations are supported through the politics of the United States as their host country, especially through its regimes and enforcement of copyright law $(2015,100-120)$. Reinforcing earlier critiques of technological instrumentalism, these contemporary forms of platform imperialism embed specific "commercial and ideological values" - ones that derive from and extend the dominance of U.S.-based TNCs and thereby the United States $(2015,185)$. Contra early, specifically Habermasian and feminist visions of the internet as democratizing, Jin summarizes: "Instead of developing a public sphere, these platforms are enhancing the corporate sphere ..." (ibid). Worse still, contra promises of greater democracy, equality, etc., the primary effects of platform imperialism will "...intensify the 
asymmetrical power relationships between countries possessing platforms and countries using platforms invented in the U.S.” (ibid).

\section{Striking back: resistance and transformation}

It appears that early dreams for an internet fostering democracy through affordances for rational debate, deliberation, and consensus-building have all but evaporated in the face of a complete collusion between transnational capitalism, platform providers, and governments bent on complete surveillance. Following Huxley and Postman, we as consumers and "users" collude with these processes as well. As the "Privacy Paradox" indexes, the vast majority of us may express concerns about protecting privacy online: but vanishingly few of us are willing to do anything about it, beginning with investing modest sums in software and procedures that would provide greater security. More broadly, it appears that the self-commodification processes fostered especially by social media - processes of packaging and re-presenting ourselves as a "brand," as fitting into a purely commercialized image of a good life, etc. - increasingly dominate our online activities and engagements.

But perhaps resistance is not futile. As Nico Carpentier (2011) reminds us, "power" is complex and dynamic, and history is non-linear: the future is not fully and completely determined by the patterns and developments of the past and present, but often unfolds in new and surprising ways. More metaphorically: there may well be cracks in these hegemonic systems and powers - sites and spaces that, as exemplified in Bakardijeva's notion of subactivism, open up new possibilities of resistance and transformation.

\section{Edward Snowden and Max Schrems: Privacy vs. the National Security Agency}

In fact, there are recent and striking examples of the power of states, international organizations, and even individuals, to speak out and occasion reform. Our first 
example is Edward Snowden's dramatic revelations of the more or less total Orwellian - surveillance programs of the U.S. National Security Agency. These revelations in turn played a central role in the suit brought by Max Schrems against Facebook in 2012 before the Court of Justice of the EU. Facebook argued that the socalled Safe Harbour agreement insured that the data of EU citizens would enjoy the same privacy protections required by EU law when transferred to the US. To the contrary, Snowden made clear that the NSA was in fact collecting personal data in direct violation of EU requirements. In 2015, the Court declared the Safe Harbour agreement invalid and insisted that "all transfers of data must end" (Wakefield 2017).

On the one hand, the Schrems case demonstrates that international institutions such as the EU Court of Justice can still curb transnational corporations. But whether and how subsequent arrangements - such as "standard contract clauses," along with ever more obtuse Terms of Service (ToS) agreements - will succeed in protecting such basic rights as privacy rights, remains an open question and struggle.

\section{Freedom of expression and cultural memory: Norway vs. Facebook}

More recently, in one of many "Facebook rebellions" (my term) - i.e., uprisings by multiple users that sometimes force the company to in fact change its ways - prominent Norwegian activists, editors, and, indeed, the Prime Minister Erna Solberg, confronted Facebook with yet one more problematic example of how its censorship practices and policies work against legitimate freedom of expression.

As part of a world-wide protest against Facebook's censorship in August and September, 2016, large numbers of activists posted the iconic picture of "the napalm girl," i.e., 9-year old Kim Phúc, running naked in terror and pain from a napalm bombing of her Vietnamese village. Facebook's algorithms could only clumsily analyze the "the napalm girl" as one of nudity, and so the postings were systematically 
removed. The confrontation with Facebook escalated as both Espen Egil Hansen, the editor of Norway's largest newspaper, Aftenposten, and Prime Minister Erna Solberg likewise posted the image on their pages. Facing increasing protests, Facebook backed down - an important victory for freedom of expression advocates (Levin, Wong, and Harding 2016)

This episode exemplifies the larger struggles between nation-states, whose existence and primary obligations turn on basic democratic rights to privacy and freedom of expression, among others - and the TNCs such as Facebook, Google, Apple, and Microsoft. A key issue here is how these corporations and their services became defined in law from the 1970s forward. Briefly, traditional media such as newspapers and then telephone, radio and TV are traditionally defined as "common carriers": as such, they are regulated according to "the common carriage principle that guarantees nondiscriminatory electronic transmission of message content" (Lentz 2011, 433). This amounts to protection of freedom of speech - at least insofar as common carriers are not allowed to interfere with expression that takes place through their media. But early law (starting in 1966) shifted the definition of developing computerized communications services into the category of "enhanced services," i.e., services that fall outside the regulations of common carriers (Lentz 2011, 433f., 437ff.). From a legal perspective, despite the fact that the transnational corporations provide us with a wealth of communication venues as well as content - i.e., they not only resemble but increasingly displace the roles and functions of traditional media such as newspapers, radio, and TV - as enhanced services they are not subject to the laws and regulations that would require, for example, that freedom of expression be respected and protected. Hence, Facebook, Google, and so on, are perfectly within their legal rights - at least currently to censor and remove whatever materials they deem objectionable for whatever reason. 
Nonetheless, it appears that there are increasing pressures - if not overly so in the United States, but certainly in the European Union and Scandinavia -favoring national and international regulation of the major platforms precisely as common carriers and content providers.

\section{Beyond Huxley and Orwell?}

Alongside these growing demands for regulation in the name of preserving democratic rights - indeed, democratic polity itself - a number of recent developments mark out further paths towards resistance and transformation.

\section{Designers and engineers as virtuous agents?}

Contra the technological instrumentalism that dominated especially U.S. presumptions regarding technology in the early 1990s, the past two decades have witnessed a growing recognition of the critical importance of designing these technologies in ways that aim to ensure more beneficent implementations and impacts. Some of these developments reflect decades of conferences fostering dialogue and collaboration between philosophers and computer science professionals (e.g., the International Association for Computing and Philosophy (IACAP) and the International Society for Ethics and Information Technology (INSEIT)). More recently, however, dramatic new initiatives primarily within the technology and design communities themselves cluster about design strategies grounded in virtue ethics.

Virtue ethics, most simply, begins with the question "What must I do - and become - in order to be content?" - where contentment refers to a deep-seated experience of satisfaction, such as accompanies our efforts to learn or acquire new and often difficult skills or abilities. These efforts thus require first of all the virtues of patience and perseverance if we are to succeed (Vallor 2016). When we do succeed, we thereby add to our repertoire of capacities that foster contentment in their own right, as 
well as lead to a sense of flourishing, of enjoying a good life. This is first of all because such virtues are essential to the relationships, such as deep friendship and long-term intimate relationships, universally acknowledged as contributing to flourishing and good lives,

Virtue ethics thus articulates a sense of the good life that goes beyond - though not necessarily in contradiction to - otherwise common design norms such as instrumental efficiency, convenience, and maximizing corporate profit. Happily, there are many striking and important examples of how virtue ethics is being introduced into the foundations of design: one of the most influential is the work of Sarah Spiekermann (2016). Spiekermann develops here a textbook for design based precisely on virtue ethics: our technologies, quite simply, should be designed with a view towards how they enable and support our experiences of contentment and flourishing. The book not only stands as a watershed publication in the expanding interest among design communities in virtue ethics: along with Vallor's work (2016), it further provides a primary ethical foundation for the recently inaugurated project of "The IEEE Global Initiative for Ethical Considerations in Artificial Intelligence and Autonomous Systems." Given the preeminent role of the IEEE (Institute of Electrical and Electronics Engineers) in setting standards worldwide for technologies and technology design - and given the ever-more central importance of $\mathrm{AI}$ and autonomous systems in our technological lives - that virtue ethics is to be taken on board in these designs from the outset is a hopeful sign.

\section{The emergence of slow tech?}

"Slow tech" is an increasingly prominent approach to ICT design that builds on both Scandinavian design traditions begun in the early 2000 s and is inspired more broadly by the Slow Food movement. As circumscribed by two of its foremost developers and advocates, Norberto Patrignani and Diane Whitehouse (2018), slow tech 
... offers people more time for reflection and for the processes needed to design and use ICT that takes into account human well-being (good ICT), the whole life cycle of the materials, energy, and products used to create, manufacture, power, and dispose of ICT (clean ICT), and the working conditions of workers throughout the entire ICT supply chain (fair ICT). (1)

As the emphasis on "human well-being" signals, Slow Tech likewise orients itself towards the virtue ethics' emphases on flourishing and good lives. Moreover, Slow Tech attends to the increasingly urgent demands of both environmental sustainability and justice and fairness in work and labour. Happily, these overarching ethical norms are not simply theoretical. Rather, Patrignani and Whitehouse can point to three "Slow Tech companies" - including Olivetti and Fairphone - that exemplify slow tech design principles and values.

\section{Provisional conclusions?}

These recent and emerging developments provide further instantiations and/or extensions of what Bakardijeva first characterized as subactivism - in my terms, savvy uses and approaches to ICTs in general and internet-facilitated communication in particular, that establish potentially emancipatory middle grounds between the poles of Orwellian and Huxleyan dystopias, on the one hand, and grand Habermasian and feminist utopias on the other. While the powers of total state surveillance and platform imperialism, especially as undergirded by the contemporary United States, may well seem unstoppable and inescapable - these counter-movements argue that resistance is not futile.

Indeed, there are a number of additional strategies and approaches emerging as as part and parcel of a contemporary turn towards a "post-digital era." Here, the all-butexclusive fascination with "the digital" in previous decades is increasingly offset by efforts to restore appropriate weight and significance to the larger elements of our 
lifeworld, beginning with our phenomenological and existential experiences of human embodiment in relationships with others, that are both and beyond any simple binary of "the analogue" vs. "the digital" (cf. Lindgren 2017, 295-298). Using cash, buying physical books, vinyl records, DVDs, rediscovering analogue photography and so on are not simply ways of better grounding our lives in the analogue and embodied world: they are at the same time practices that reduce our digital footprints, increase our privacy, and push back on the otherwise comprehensive colonization of our lives as mere data that primarily serves the interests of the TNCs and states bent on total surveillance.

But while these examples (and still others) might give us hope, they also come at a price. First and foremost, as the inter-weavings here with virtue ethics suggests, these approaches require all of us - most especially as consumers of technologies designed for our (ostensible) convenience - to resist the Huxleyan reduction to simple consumers and commodified brands. Rather, these movements and strategies will succeed only insofar as more and more of us take an active responsibility for how we engage and navigate our lives in such a post-digital era. In these directions, the Enlightenment motto, sapere aude - have the courage to think (and act) for yourself - remains trenchant. As Shannon Vallor has made most especially clear, we must take on anew the responsibilities of developing those virtues required for good lives in a technological era - virtues such as honesty, care, transparency, and so on $(2016,119-155)$. And as the growing DIY (Do it yourself), Maker and Hacker workshops, etc. exemplify, we as "users" of these technologies must specifically take on the (life-long) project of becoming more familiar with how they work "under the hood," so that we are thereby better equipped to understand how we can use them in ways that indeed contribute to good lives of flourishing, both as engaged citizens of democratic societies and as human beings per se. 
More virtuous designs and political pressures towards regulation will be critical to preserving democratic norms, principles, and deliberative processes. In the meantime, however, it will only be through such renewed and active engagement that we can reduce the Huxleyan risk of falling in love with the technologies of our enslavement. This is manifestly not the inauguration of an electronic global village with perfect democratic deliberation. But it is also how we can push back - ideally, at both local (subactivism) and national levels - against the more Orwellian forces of platform imperialism and state surveillance.

\section{References}

Bakardjieva, Maria. 2009. Subactivism: Lifeworld and Politics in the Age of the Internet. The Information Society, 25: 91-104.

Becker, Barbara and Wehner, Josef. 2001. Electronic Networks and Civil Society:

Reflections on Structural Changes in the Public Sphere," in Charles Ess (Ed.), Culture, Technology, Communication: Towards an Intercultural Global Village. Albany: State University of New York Press, pp. 65-85.

Carpentier, Nico. 2011. Policy's Hubris: Power, Fantasy, and the Limits of (Global) Media Policy Interventions. In Robin Mansell and Marc Raboy (eds.), The Handbook of Global Media and Communication Policy, 113-128. Oxford: Blackwell.

Dean, Jodi. 2009. Democracy and Other Neoliberal Fantasies: Communicative Capitalism and Left Politics. Durham, NC: Duke University Press.

Ess, Charles. 1996. The Political Computer: Democracy, CMC, and Habermas. In C. Ess (ed.), Philosophical Perspectives on Computer-Mediated Communication, 197-230. Albany, NY: State University of New York Press.

Ess, Charles. 2004. Computer-Mediated Colonization, the Renaissance, and Educational Imperatives for an Intercultural Global Village. In Robert Cavalier (ed.), The Internet and Our Moral Lives, pp. 161-193. Albany, NY: SUNY Press. Habermas, Jürgen. 1983. Moralbewußtsein und Kommunikatives Handelns, Frankfurt am main: Suhrkamp.

Howard, Philip N. and Muzammil M. Hussain. Democracy's Fourth Wave?: Digital Media and the Arab Spring. Oxford: Oxford University Press, 2013. 
Jin, Dal Yong. 2015. Digital Platforms, Imperialism and Political Culture. New York and London: Routledge.

Lentz, Roberta G. 2011. Regulation as Linguistic Engineering. In Robin Mansell and Marc Raboy (eds.), The Handbook of Global Media and Communication Policy, 432-448. Oxford: Blackwell

Levin, Sam, Wong, Julie Carrie, and Harding, Luke. 2016. Facebook backs down from 'napalm girl' censorship and reinstates photo. The Guardian, Sept. 9.

https://www.theguardian.com/technology/2016/sep/09/facebook-reinstates-napalmgirl-photo

Lindgren, Simon. 2017. Digital Media and Society: Theories, topics and tools.

London: Sage.

Patrignani, Norberto and Whitehouse, Diane. 2018. Slow Tech and ICT: A

Responsible, Sustainable and Ethical Approach. London: Palgrave Macmillan Phelan, Sean and Dahlberg, Lincoln. 2011. Discourse Theory and Critical Media Politics. London: Palgrave Macmillan.

Postman, Neil. 1984. Amusing Ourselves to Death.

Spiekermann, Sarah. 2016. Ethical IT innovation: A value-based system design approach. New York, NY: Taylor \& Francis.

Sunstein, Cass. 2001. Republic.com. Princeton, NJ: Princeton University Press.

Thorseth, May. 2008. Reflective judgment and enlarged thinking online. Ethics and Information Technology 10:221-231. DOI 10.1007/s10676-008-9166-6

Vallor, Shannon. 2016. Technology and the Virtues: Towards a Future Worth Wanting. Cambridge, MA: MIT Press.

Wakefield, Jane. 2017. Fresh twist in Facebook data transfer row. BBC. (October 3, 2017). http://www.bbc.com/news/technology-41482201 